\title{
The effect of protein and energy deficiency on skin glycosaminoglycan levels in the rat
}

\author{
BY JANE S. N. KAGGWA* \\ MRC Dunn Nutrition Unit, Dunn Nutritional Laboratory, University of Cambridge and \\ Medical Research Council, Milton Road, Cambridge CB4 $1 \mathrm{XJ}$
}

(Received 1 October 1985 - Accepted 14 April 1986)

\begin{abstract}
1. The effects of protein-deficient and energy-deficient diets on the concentrations of skin glycosaminoglycans (GAGs) and collagen were studied in young rats.

2. In Expt 1, comparisons were made between animals fed on a control (C) diet (protein:energy $(P: E) 0 \cdot 210)$, a low-protein (LP) diet (P: E 0.032) and a very-low-protein (VLP) diet (P: E 0.005) ad lib. Skin GAGs and collagen concentrations were determined at intervals as the animals became malnourished and when some of those fed on the VLP diet started showing signs of oedema. Concurrently, plasma albumin concentrations were determined to assess the extent of hypoalbuminaemia. With prolonged severe protein deficiency all GAGs species were reduced below normal levels. Collagen concentration decreased with prolonged protein deficiency. Protein-deficient rats developed hypoalbuminaemia.

3. In Expt 2, comparisons were made between animals fed on the C, LP and VLP diets ad lib. and others given the $\mathrm{C}$ diet in restricted amounts sufficient to maintain body-weights identical to those fed on LP or VLP diets $a d l i b$. Energy-deficient rats, wasting at rates similar to protein-deficient ones, had higher skin GAGs concentrations than those in protein-deficient or control animals. With prolonged malnutrition, collagen concentrations were similar in protein- and energy-deficient animals and lower than those observed in control animals. Plasma albumin concentrations in energy-deficient animals were above starting values, except in severely energy-deficient animals at the end of the experiment. Protein-deficient animals developed hypoalbuminaemia.

4. In conclusion, the present study has shown that the main difference between prolonged severe protein deficiency and energy deficiency in the rat is that skin hyaluronic acid concentration is higher than normal in energy deficiency but below normal levels in prolonged severe protein deficiency. Initially skin collagen concentrations are higher than normal in both protein- and energy-deficient animals. However, with prolonged malnutrition the concentrations are reduced.
\end{abstract}

Skin changes constitute an important clinical feature in kwashiorkor (Williams, 1935; Alleyne et al. 1977). Protein malnutrition is known to affect the metabolism of most body proteins. Collagen is the major structural protein in skin and is essential for its mechanical strength and stability. For this reason any significant loss of skin collagen would have disastrous effects. In view of these considerations several studies have been carried out to determine skin collagen concentrations in experimental protein and energy deficiency (Cabak et al. 1963; Anasuya \& Narasingo Rao, 1970; Angeleli et al. 1978; Arumugham \& Bose, 1979) and in children suffering from protein-energy malnutrition (Picou et al. 1966; Halliday, 1967; Vasantha et al. 1970). However, observations from these studies are conflicting.

Glycosaminoglycans (GAGs), the other important components of skin, have not received the same attention. These polysaccharides entrap tissue fluid to form a gel that fills the interfibrillar space in connective tissues. Vasantha (1970) reported a higher hexosamine content (total GAGs) in skin from protein- or energy-deficient rats than in that from controls. Vasantha (1979) observed no difference between the hexosamine content in skin of protein-deficient animals and that of energy-deficient ones. Recently, Arumugham \& Bose (1979) have reported higher contents of total GAGs and a non-sulphated fraction in skin of protein-deficient rats compared with those in controls. However, the monosulphated and highly sulphated fractions were higher in the latter.

* Present address: Department of Chemistry, University of Zambia, PO Box 32379, Lusaka, Zambia. 
The present study was undertaken to determine the effects of protein and energy deficiency on the composition of rat skin, with particular reference to GAGs. Concurrently skin collagen concentration was determined and plasma albumin concentrations were measured to assess the extent of hypoalbuminaemia.

\section{MATERIAL AND METHODS}

\section{Animals}

Hooded male rats from a pathogen-free colony were used in the experiments. They were raised in groups of eight per litter and weaned when 3 weeks old. After weaning they were caged individually.

\section{Diets}

A stock pellet diet (Spillers Laboratory Animal Service, Barking, Essex) containing $215 \mathrm{~g}$ protein $/ \mathrm{kg}$ was used after weaning. The three synthetic diets subsequently given were the control (C), low-protein (LP) and very-low-protein (VLP) diets described by Coward et al. (1977), with values for protein:energy (P:E) of $0.210,0.032$ and 0.005 respectively. The diets were virtually isoenergetic. Water was provided ad lib.

\section{Experimental design}

Two series of experiments were performed. The first series (Expt 1) was carried out to investigate the effect of protein deficiency on skin GAGs and collagen concentrations. Ninety-one rats were assigned randomly to thirteen groups of seven animals each. They were 6 weeks old and their mean body-weight was 161 (SE 1) g. The animals were then allocated to diets C, LP and VLP ad lib. (four groups per diet). The remaining group was killed at this stage to provide initial values. All animals were weighed once weekly. One group from each diet was killed at weeks 3,7 and 12 and when some animals fed on diet VLP started showing signs of oedema (week 19).

The second series of experiments (Expt 2) was carried out to compare the effect of protein deficiency and energy deficiency on skin GAGs and collagen concentrations. The rats used were 5 weeks old and their mean body-weight was 127 (SE 3) g. Seventy-seven animals were divided at random into eleven groups of seven animals each. Six groups were allocated to diets C, LP and VLP (two groups per diet). These animals received diets C, LP and VLP ad lib. respectively. The two groups allocated to diet LP were paired by weight with two other groups given restricted amounts of diet $\mathrm{C}$, dietary regimen $\mathrm{C}(\mathrm{rLP})$, just sufficient to maintain body-weights identical to those fed on diet LP ad lib. Similarly, animals allocated to diet VLP were paired with two groups fed on more severely restricted amounts of diet C, dietary regimen C(rVLP). The remaining group was killed at the start of the experimental period. One group from each dietary regimen was killed 3 weeks later and when some animals on dietary regimen C(rVLP) died (week 10).

\section{Experimental procedures}

Preparation of tissues. Blood samples $(2-5 \mathrm{ml})$ were collected into heparinized syringes by cardiac puncture while the animal was under diethyl ether anaesthesia. Plasma was prepared and stored at $-20^{\circ}$ until analysis.

The skins were stripped off the carcasses and fur removed by shaving. Loose muscle and fat were dissected from the skin which was then chopped into small pieces and dried. Dry skin was defatted using two $24 \mathrm{~h}$ extractions with chloroform-methanol $(2: 1, \mathrm{v} / \mathrm{v})$.

Analysis of tissues. Plasma albumin concentration was determined by an automated bromocresol green reaction (Northam \& Widdowson, 1967) using human serum as a 
standard. To correct for different dye-binding capacities of human and rat albumin a factor of 0.78 was applied to the values. Samples of dry defatted skin (approximately $0 \cdot 1 \mathrm{~g}$ ) were hydrolysed in $6 \mathrm{M}$-hydrochloric acid at $105^{\circ}$ for $18 \mathrm{~h}$ in sealed tubes. The hydroxyproline content of the hydrolysates was determined by the chloramine $\mathrm{T}$ method described by Kivirikko et al. (1967).

Dry defatted skin samples (approximately $1.0 \mathrm{~g}$ ) were digested with papain $(E C 3.4 .22 .2$ ) as described by Scott (1960). The digest was then clarified by passing through Hyflosupercel. Cetylpyridinium chloride $(50 \mathrm{~g} / \mathrm{l} ; 2 \mathrm{ml})$ was added to the digest and water $(5 \mathrm{vol}$.) was then added slowly while rapidly stirring. As the salt concentration dropped, the GAGscetylpyridinium complexes were selectively precipitated. The mixture was centrifuged for $30 \mathrm{~min}$ at $17300 \mathrm{~g}$. The precipitate was washed with $0.05 \mathrm{M}$-sodium chloride and dissolved in $n$-propanol-water $(2: 1, \mathrm{v} / \mathrm{v} ; 6 \mathrm{ml} / \mathrm{g}$ starting material). Saturated sodium acetate ( 3 vol.) in ethanol was added. After mixing, the suspension was stored overnight at $4^{\circ}$, then centrifuged for $30 \mathrm{~min}$ at $17300 \mathrm{~g}$. The precipitate was washed successively with ethanol, ethanol-ether $(1: 1, \mathrm{v} / \mathrm{v})$ and finally with diethyl ether. After drying at room temperature the GAGs were dissolved in water for subsequent analysis ( $4 \mathrm{ml}$ water $/ \mathrm{g}$ starting material).

Total GAGs concentration was determined by measuring uronic acid using the modified carbazole method of Bitter \& Muir (1962). For identification and quantification of individual GAGs, electrophoresis on cellulose acetate was used. Samples for electrophoresis were prepared by incubating $1 \mathrm{ml}$ of the isolated GAGs with $50 \mu \mathrm{g}$ ribonuclease $\mathrm{A}(E C 3.1 .27 .5)$ and $50 \mu \mathrm{g}$ deoxyribonuclease 1 (EC 3.1.21.1) (Sigma Chemical Co., Poole, Dorset) for $10 \mathrm{~min}$ at $37^{\circ}$. This treatment reduced viscosity of the samples and prevented streaking during electrophoresis. The samples were then freeze-dried and redissolved in $0.3 \mathrm{ml}$ water for electrophoresis.

Electrophoresis and quantification of individual GAGs were then carried out as described by Newton et al. (1974). For the separation of hyaluronic acid (HA) and dermatan sulphate (DS) the buffer used was $0 \cdot 2 \mathrm{M}$-calcium acetate, $\mathrm{pH} 7 \cdot 25$. Barium acetate buffer $(0.1 \mathrm{M}, \mathrm{pH} 5.8)$ was used for the separation of heparin (Hep) and chondroitin 4-sulphate (Chs-4).

\section{Statistical analysis}

The significance of differences between two mean values was calculated using the Student's $t$ test. $P \leqslant 0.05$ was regarded as significant.

\section{RESULTS}

Expt 1

Growth and appearance of animals. Animals fed on diet VLP gradually lost weight and by the end of the experiment had lost, on average, $45 \%$ of their original body-weight ( $161 \mathrm{~g})$. Although in some animals transient oedema was observed in the subcutaneous tissues of the neck and cheeks by week 18, this was not reflected by an increase in body-weight. In some animals hair changes were observed after 10 weeks and most of them developed skin lesions on their tails and paws. Animals fed on diet LP lost $7 \%$ of their initial mean body-weight during the first 2 weeks of the experiment. Thereafter the body-weight increased slightly and by week 19 the animals had increased their mean body-weight by $46 \%$. The control animals grew steadily throughout the experiment and by week 19 they had increased their mean body-weight by $223 \%$.

Plasma albumin concentration. Changes in plasma albumin concentration are shown in Fig. 1. During the first 3 weeks the concentration in animals fed on diets LP and VLP decreased. The concentration continued to fall in animals fed on diet VLP and at weeks 


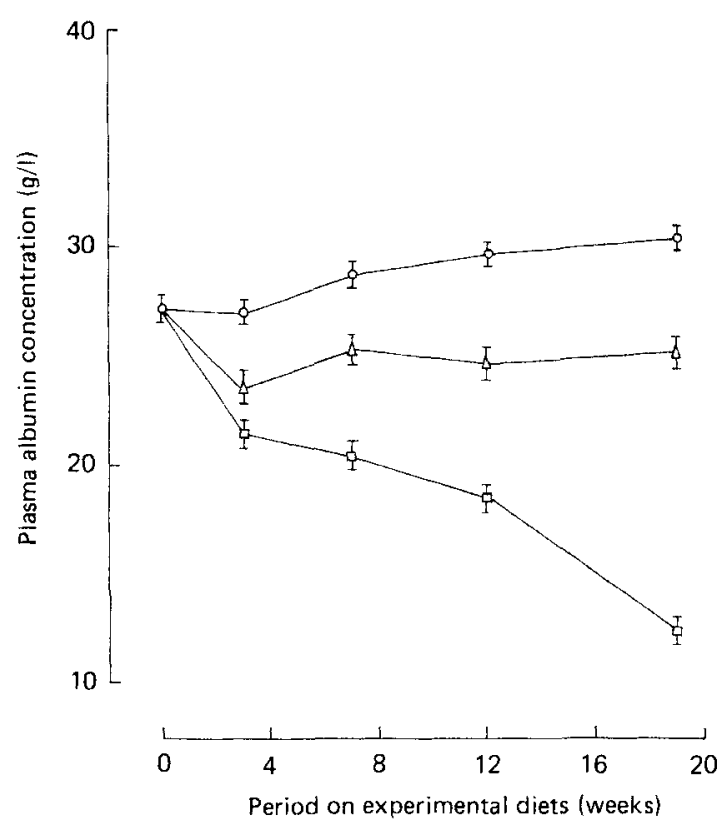

Fig. 1. Plasma albumin concentration $(g / 1)$ in rats fed on control $(O)$, low-protein $(\triangle)$ and verylow-protein $(\square)$ diets ad lib. Values are means, with their standard errors represented by vertical bars $(n$ 7). For details of diets, see p. 330.

12 and 19 the values were significantly lower $(P<0.001)$ than those in animals fed on diets $C$ and LP killed at the same time. At all time-intervals the concentrations in animals fed on diet LP were significantly lower $(P<0.001)$ than those in control animals killed at the same time. Albumin concentrations in control animals increased slightly during the experiment so that at weeks 12 and 19 the values were significantly higher $(P<0.01)$ than those of animals killed at the start.

Hydroxyproline concentration in skin. Fig. 2 shows the variations in skin hydroxyproline concentration. The concentration rose initially in all animals, so that at week 3 the values for all animals were significantly higher $(P<0.001)$ than those in animals killed at the start. In the control animals the concentration continued to rise, reaching a plateau value of 134.9 (SE 3.5) $\mathrm{mg} / \mathrm{g}$ at week 12 . The concentration in animals fed on diet VLP reached a maximum value of 118.2 (SE 6.2) $\mathrm{mg} / \mathrm{g}$ at week 7 and then decreased to a constant value at week 12 . At this time the concentration was still significantly higher $(P<0.001)$ than that in animals killed at the start.

There was no consistent difference between animals fed on diet LP and those fed on diet VLP, although by the end of the experiment the latter exhibited a significantly lower $(P<0.01)$ skin hydroxyproline concentration.

GAGs concentrations in skin. The major GAGs species in rat skin were HA and DS, with small amounts of Hep and Chs-4. At all time-intervals the concentration of Chs-4 was too low to be estimated by the electrophoretic method used.

The changes in the GAGs concentrations of skin are shown in Fig. 3(a-d). All GAGs species decreased with age, particularly in the early stages of the experiment. Apart from the high HA value in skin from animals fed on diet VLP at week 12, the pattern of change 


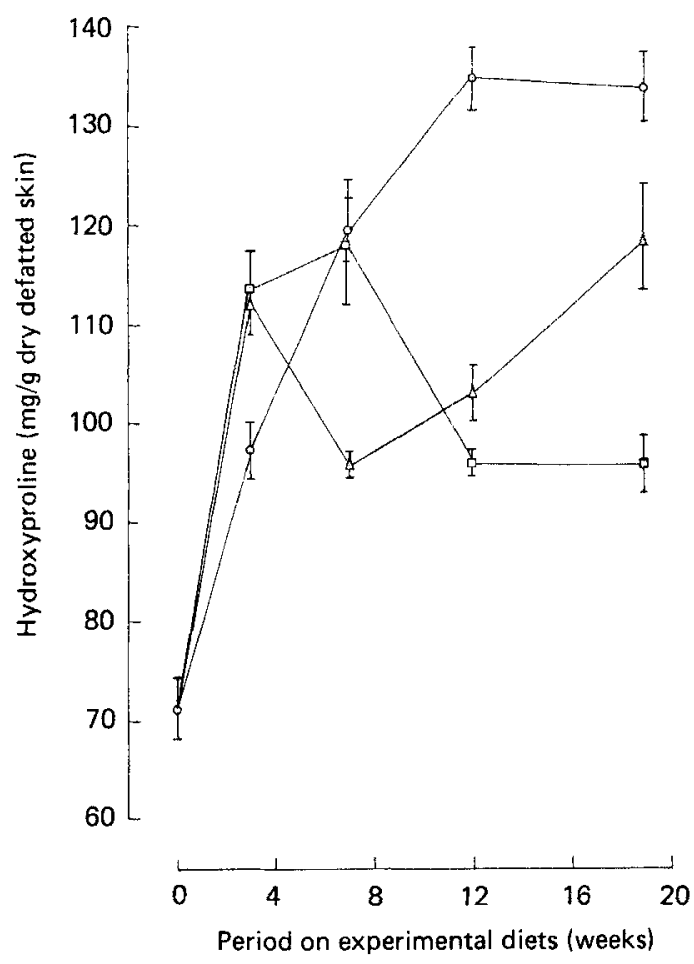

Fig. 2. Hydroxyproline concentration ( $\mathrm{mg} / \mathrm{g}$ dry defatted tissue) in skin from rats fed on control $(O)$, low-protein $(\triangle)$ and very-low-protein $(\square)$ diets ad lib. Values are means, with their standard errors represented by vertical bars $(n 7)$. For details of diets, see p. 330.

for all species was almost the same in all groups although skin from animals fed on diet VLP had lower values. However, there was no clear difference between the level of uronic acid in skin from animals fed on diet LP and that from the controls.

\section{Expt 2}

Growth, behaviour and appearance of animals. The effects of the five dietary regimens on the growth of animals are shown in Fig. 4. Although animals used in Expt 2 were younger than those used in Expt 1 the growth patterns and appearance of animals fed on diets C, LP and VLP ad lib. were similar in the two experiments. After 1 week animals on dietary regimen $\mathrm{C}(\mathrm{rVLP})$ were much less active than those fed on diet VLP ad lib., although they had similar body-weights. By the 2 nd week animals on dietary regimen C(rVLP) frequently exhibited a syndrome involving shivering, but signs of protein deficiency (skin lesions and hair changes) were not observed in these animals. Those on dietary regimen C(rLP) seemed to be normal but were not as active as those fed on diet LP ad lib. After 10 weeks, two animals on dietary regimen C(rVLP) died suddenly. By this time animals on this dietary regimen had lost, on average, $35 \%$ of their original body-weight and those fed on diet VLP ad lib. had lost $36 \%$ of their initial body-weight. Within the same period animals fed on diet LP ad lib. had gained $24 \%$ of their original body-weight and those on dietary regimen $\mathrm{C}(\mathrm{rLP})$ had increased their body-weight by $25 \%$. 

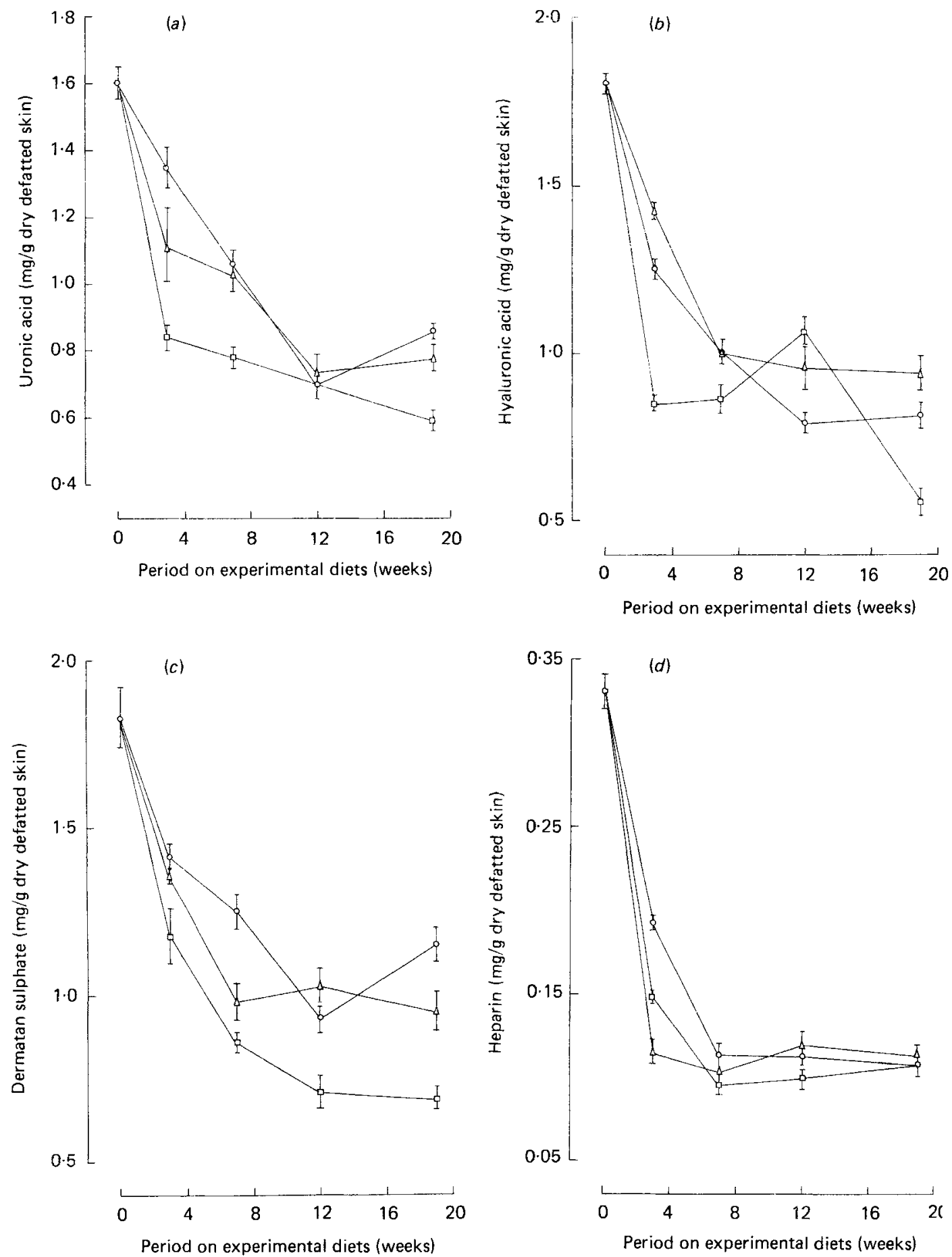

Fig. 3. (a) Uronic acid, (b) hyaluronic acid (c) dermatan sulphate and $(d)$ heparin concentrations $(\mathrm{mg} / \mathrm{g}$ dry defatted tissue) in skin from animals fed on control $(O)$, low-protein $(\triangle)$ and very-low-protein $(\square)$ diets $a d l i b$. Values are means, with their standard errors represented by vertical bars $(n 7)$. For details of diets, see p. 330. 


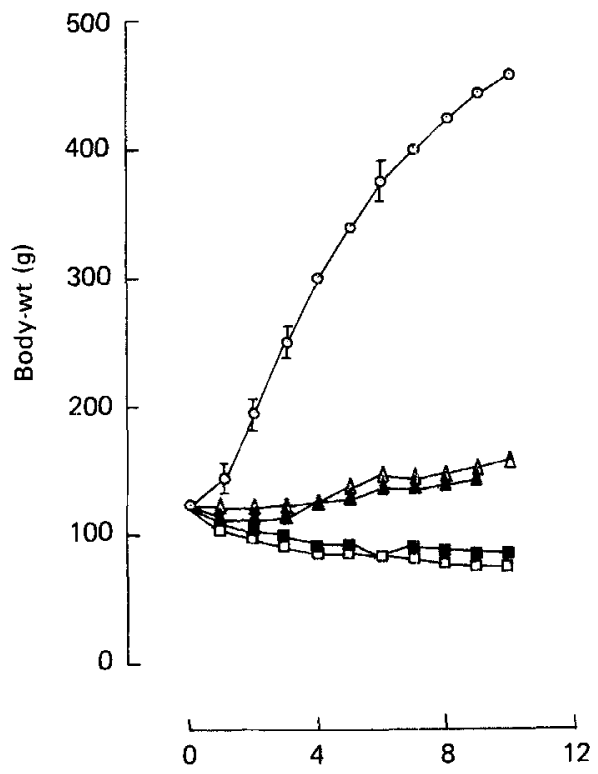

Period on experimental diets (weeks)

Fig. 4. Body-weights $(\mathrm{g})$ of rats fed on control $(O)$, low-protein $(\mathrm{LP}, \triangle)$ and very-low-protein (VLP, $\square)$ diets ad $i h$., and restricted amounts of the control diet (C(rLP), $\Delta ; C(r V L P), \square)$. Values are means, with their standard errors represented by vertical bars ( $n$ 7, except for dietary regimen VLP ad lib. at 3 weeks, $n$ 6, and dietary regimen C(rVLP) at 10 weeks, $n$ 4). For details of diets, see p. 330.

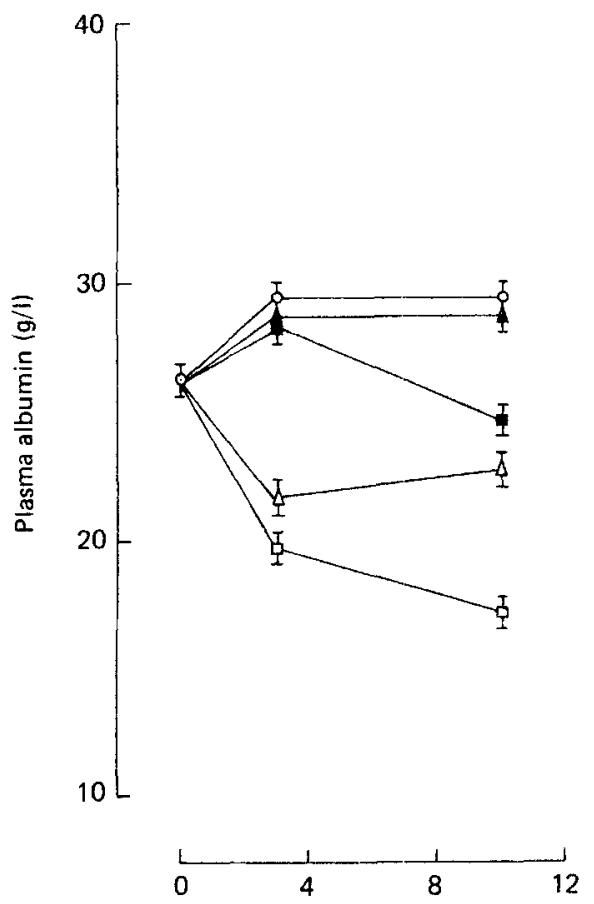

Period on experimental diets (weeks)

Fig. 5. Plasma albumin concentrations $(\mathrm{g} / \mathrm{l})$ in rats fed on control $(\mathrm{O})$, low-protein $(\mathrm{LP}, \triangle)$ and very-low-protein (VLP, $\square$ ) diets $a d l i b$., and restricted amounts of the control diet (C(rLP), $\Delta ; C(r V L P)$, $\square)$. Values are means, with their standard errors represented by vertical bars $(n 7$ except for dietary regimen VLP ad lib. at 3 weeks, $n$, and dietary regimen C(rVLP) at 10 weeks, $n 4$ ). For details of diets, see p. 330. 


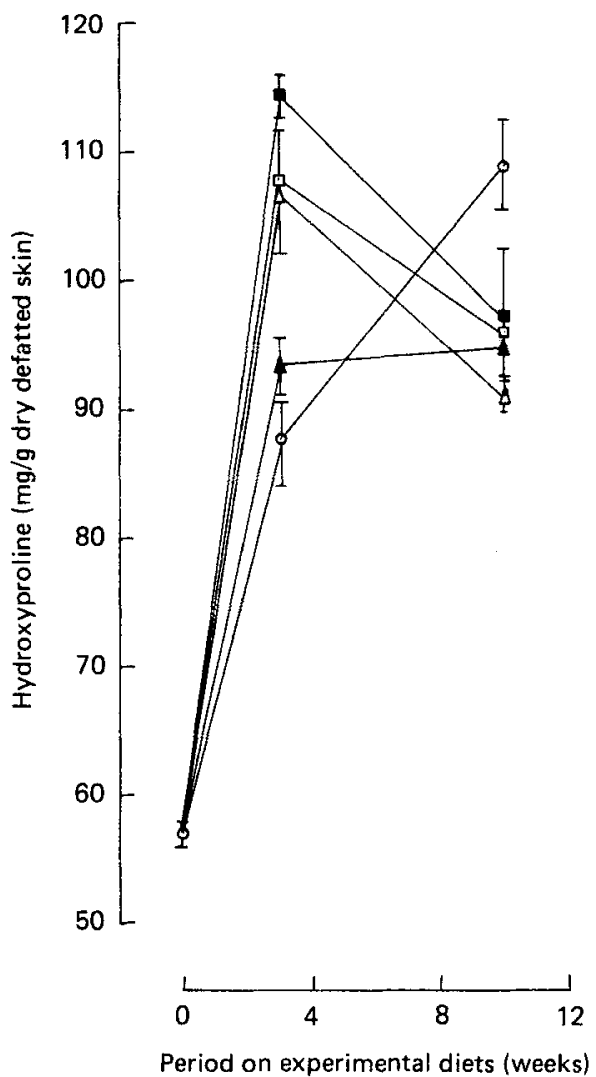

Fig. 6. Hydroxyproline concentration (mg/g dry defatted tissue) in skin from rats fed on control $(O)$, low-protein (LP, $\triangle$ ) and very-low-protein (VLP, $\square$ ) diets ad lib., and restricted amounts of the control $\operatorname{diet}(\mathrm{C}(\mathrm{rLP}), \boldsymbol{\Delta} ; \mathrm{C}(\mathrm{rVLP}), \mathbf{D})$. Values are means, with their standard errors represented by vertical bars ( $n$ 7, except for dietary regimen VLP ad lib. at 3 weeks, $n$, and dietary regimen C(rVLP) at 10 weeks, $n$ 4). For details of diets, see p. 330.

Plasma albumin concentration. The variations in plasma albumin concentration (Fig. 5) in animals fed on diets C, LP and VLP ad lib. were similar to those described in Expt 1. Although animals receiving restricted amounts of diet $\mathrm{C}$ and those fed on diet LP or VLP ad lib. had similar body-weights, plasma albumin concentrations in the 'restricted' animals were significantly higher $(P<0.001)$. The concentrations in the 'restricted' animals were above the starting values except at week 10 in those on dietary regimen C(rVLP) but animals fed on diets LP and VLP ad lib. developed hypoalbuminaemia.

Hydroxyproline concentration in skin. In animals fed on diets C, LP and VLP ad lib. the variations in skin hydroxyproline concentration (Fig. 6) were similar to those observed in Expt 1. The concentration increased initially in animals on restricted amounts of diet $\mathrm{C}$

Fig. 7. (a) Uronic acid, (b) hyaluronic acid, (c) dermatan sulphate and $(d)$ heparin concentrations $(\mathrm{mg} / \mathrm{g}$ dry defatted tissue) in skin from rats fed on control $(O)$, low-protein $(L P, \triangle)$ and very-low-protein (VLP, $\square$ ) diets $a d$ lib., and restricted amounts of the control diet (C(rLP), $\Delta ; C$ (rVLP), $\mathbf{D})$. Values are means, with their standard errors represented by vertical bars ( 7 , except for dietary regimen VLP ad lib. at 3 weeks, $n 6$, and dietary regimen $C($ rVLP) at 10 weeks, $n 4)$. For details of diets, see p. 330. 

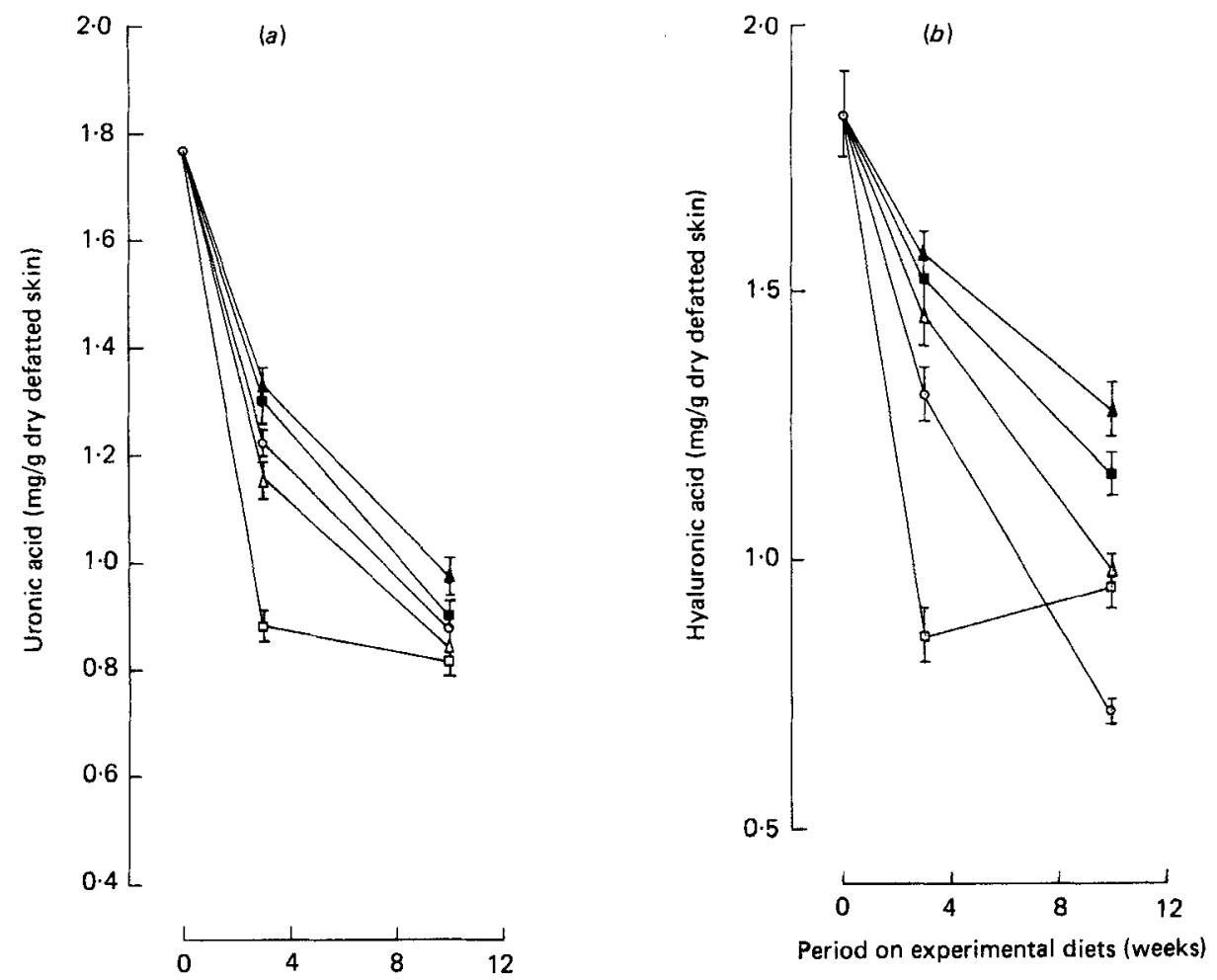

Period on experimental diets (weeks)
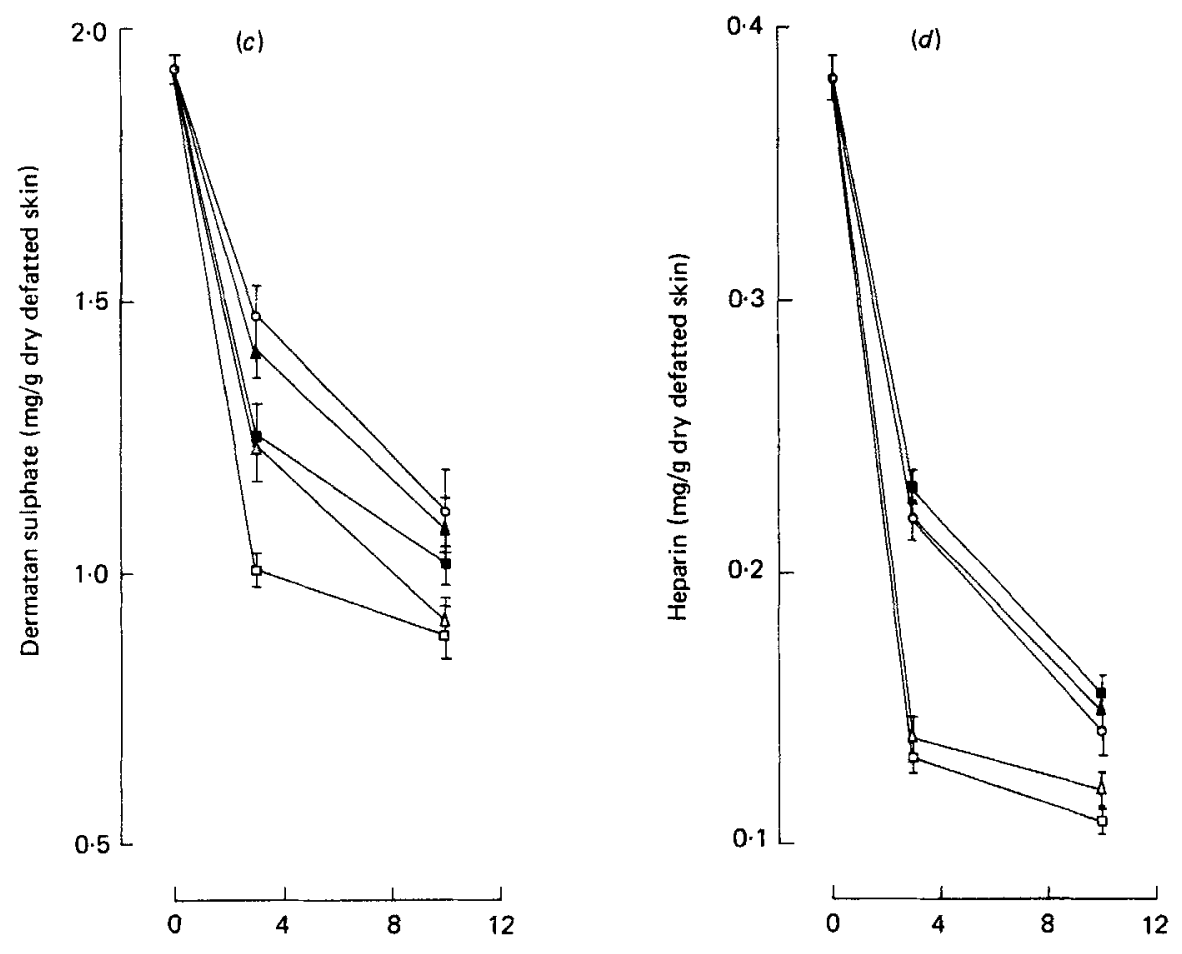

Period on experimental diets (weeks)

Period on experimental diets (weeks)

Fig. 7. For legend see opposite. 
and after week 3 it decreased slightly in animals on dietary regimen C(rVLP) but remained almost constant in those on dietary regimen $\mathrm{C}(\mathrm{rLP})$. At week 10 there was a significant difference $(P<0.01)$ between the hydroxyproline concentration in skin from animals fed on diet LP ad lib. and the concentration in those from animals on dietary regimen C(rLP). However, at this time there were no significant differences between the concentration in animals fed on diet VLP ad lib. and those on dietary regimen C(rVLP).

$G A G$ s concentration in skin. Changes in skin GAGs concentration are given in Fig. $7(a-d)$. The GAGs components of skin were the same as those observed in Expt 1 and the trends in skin from animals given diets C, LP and VLP ad lib. were similar. Skin GAGs concentrations in animals fed on the restricted control diets also decreased with age. Throughout the experiment skins from energy-deficient animals contained higher levels of all GAGs species than those from protein-deficient ones. Similarly, the levels of uronic acid and HA were higher in skin from energy-deficient animals than in that from the controls. Nevertheless, skin from controls contained the highest level of DS.

\section{DISCUSSION}

The purpose of the present study was to investigate changes in skin GAGs and collagen concentrations in protein- and energy-deficient rats. The results obtained show that all skin GAGs species were reduced below control levels in prolonged severe protein deficiency. However, no clear differences were observed between total skin GAGs (uronic acid) in animals given a $30 \mathrm{~g}$ protein $/ \mathrm{kg}$ diet (diet LP) and the controls, although skin from the former tended to have more HA whereas that from the latter contained more DS and Hep. In energy-deficient animals total skin GAGs concentrations were higher than controls and this was due to high levels of HA. Nevertheless, DS concentration in skin from energydeficient animals was below control levels and there was no clear difference between Hep concentration of skin from energy-deficient animals and that from control animals. Although skin DS concentration was below control levels in both protein- and energydeficient animals, the levels were higher in skin from the latter. These findings are different from those of Vasantha (1970) who observed a higher hexosamine content (total GAGs) in skin from protein- or energy-deficient rats compared with that from controls. In the same study Vasantha (1970) observed no differences between the hexosamine content of skins from protein-deficient animals and those from energy-deficient ones. Although hexosamine is a measure of all GAGs species, in Vasantha's (1970) study it was measured directly in skin hydrolysates. However, skin contains two types of hexosamine-containing compounds: GAGs and glycoproteins, and therefore the significance of Vasantha's (1970) findings is not clear. Arumugham \& Bose (1979) found higher uronic acid and non-sulphated GAG contents in skin from rats fed on a $60 \mathrm{~g}$ protein $/ \mathrm{kg}$ diet compared with those from controls. Their observation for uronic acid is different from the results obtained in the present study. Nevertheless, if the non-sulphated GAGs species was HA, their finding for this GAGs species is in agreement with the results obtained in the present study for skins from animals fed on a $30 \mathrm{~g}$ protein $/ \mathrm{kg}$ diet and the controls. In the same study these workers observed higher contents of monosulphated and highly sulphated GAGs species in skin from control animals than in that from protein-deficient ones, which is in agreement with findings in the present study if the monosulphated and highly sulphated species were DS and Hep respectively.

The present study has shown that initially skin collagen concentration is higher in mainourished animals than in controls, whether they are protein- or energy-deficient. However, with prolonged malnutrition the concentration is reduced. Other workers report that skin collagen concentration is increased (Picou et al. 1966; Halliday, 1967) or 
reduced (Vasantha et al. 1970) in children with protein-energy malnutrition. A similar situation has been observed in experimental animals. Cabak et al. (1963) described increased skin collagen concentration in protein- or energy-deficient rats, whereas Anasuya \& Narasingo Rao (1970), Angeleli et al. (1978) and Arumugham \& Bose (1979) observed reduced concentration.

The present study showed that the changes observed in skin collagen concentrations during the early stages of malnutrition were different from those that occurred after prolonged malnutrition. Therefore, most of the differences between the observations in experimental animals on skin collagen concentration are likely to be explained by variations in the duration of the malnutrition and the age of the animals when analyses were performed.

It may therefore be concluded that in prolonged severe protein deficiency both skin HA and collagen concentrations are below normal levels. In energy deficiency skin HA concentration is above normal levels whereas collagen is below normal levels. Since the interfibrillar material in skin is almost exclusively HA (Szirmai, 1970), the findings of the present study may have implications for cutaneous lesions observed in kwashiorkor and not marasmus.

As the main function of GAGs is to entrap tissue fluid to form a gel, reduced HA levels observed in prolonged severe protein deficiency could result in high mobility of tissue water, thus causing oedema. Further studies are needed to investigate skin GAGs contents in relation to oedema formation in malnutrition.

The author is indebted to Dr W. A. Coward and Dr R. G. Whitehead for advice and encouragement; Professor J. E. Scott, Manchester Medical School, for advice on the analysis of glycosaminoglycans; and Mr G. J. Hudson and Mr P. M. V. John for technical assistance. J.S.N.K. was in receipt of a World Health Organization Fellowship.

\section{REFERENCES}

Alleyne, G. A. O., Hay, R. W., Picou, D. I., Stanfield, J. P. \& Whitehead, R. G. (1977). In Protein-Energy Malnutrition. London: Edward Arnold.

Anasuya, A. \& Narasinga Rao, B. S. (1970). British Journal of Nutrition 24, 97-107.

Angeleli, A. Y. O., Burini, R. C. \& Campana, A. O. (1978). Journal of Nutrition 108, 1147-1154.

Arumugham, R. \& Bose, S. M. (1979). Acta Biochimica Polonica 26, 295-301.

Bitter, T. \& Muir, H. M. (1962). Analytical Biochemistry 4, 330-334.

Cabak, V., Dickerson, J. W. T. \& Widdowson, E. M. (1963). British Journal of Nutrition 17, 601-606.

Coward, W. A., Whitehead, R. G. \& Lunn, P. G. (1977). British Journal of Nutrition 38, $115-126$.

Halliday, D. (1967). Clinical Science 33, 365-370.

Kivirikko, K. I., Laitinen, O. \& Prockop, D. J. (1967). Analytical Biochemistry 19, 249-255.

Newton, D. J., Scott, J. E. \& Whiteman, P. (1974). Analytical Biochemistry 62, 268-273.

Northam, B. E. \& Widdowson, G. W. (1967). Association of Clinical and Biochemical Technical Bulletin 11, 1-6.

Picou, D., Halliday, D. \& Garrow, J. S. (1966). Clinical Science 30, 345-351.

Scott, J. E. (1960). Methods in Biochemical Analysis 8, 145-197.

Szirmai, J. A. (1970). In Advances in Biology of Skin, vol. 10, pp. 1-15. [W. Montagna, J. P. Bantley and R. L. Dobson, editors]. New York: Appleton-Century-Crofts.

Vasantha, L. (1970). American Journal of Clinical Nutrition 23, 99-104.

Vasantha, L., Srikantia, S. G. \& Gopalan, C. (1970). American Journal of Clinical Nutrition 23, $78-82$.

Williams, C. D. (1935). Lancet ii, 1151-1152. 